\title{
RECONSTRUCTION OF A MASONRY WINDMILL TOWER WITH A MULTI-BLADE WIND TURBINE, STEEL RESERVOIR AND WATER SUPPLY SYSTEM
}

\author{
PIOTR W. SIELICKI ${ }^{{ }^{*}}$ \\ ${ }^{1}$ Faculty of Civil and Transport Engineering \\ Poznan University of Technolgy (PUT) \\ M. Skłodowskiej-Curie 5, 60965 Poznan, Poland \\ e-mail: piotr.sielicki@put.edu.pl,www.put.edu.pl (*corresponding author)
}

Keywords: Windmill, Turbine, Masonry, Restoration, Water supply

\begin{abstract}
In the early 20th century, rapid industrial growth around the world enabled the development of many advanced mechanical structures. Some of these structures were successfully used to improve agricultural efficiency or increase people's comfort. Such a situation was observed in 1910 in the western part of Poland, which at the time was partitioned by Habsburg Austria, the Kingdom of Prussia, and the Russian Empire. In the city of Poznan, a Polish landlord built an advanced structure to automate his farming, using freely available wind energy. At first glance, it was a classic windmill, with a multi-blade wind turbine fixed to the top of a cylindrical masonry tower. However, some additional elements demonstrate the uniqueness of such a structure at the time. One hundred years later, the structure is located at the centre of a rapidly growing area of the city. For that reason, restoration of the tower is complex and requires the reconstruction of damaged or missing elements while observing new safety regulations. In this work, the author presents the basic assumptions necessary for the future renovation process.
\end{abstract}

\section{INTRODUCTION}

Since ancient times, many unique engineering structures have been created to support human civilisations. Most of these structures supported basic existential needs, such as the extraction, supply and storage of water. These important needs were directly connected to food production. From the heritage aqueducts in ancient Rome to the thousand-year-old Nashtifan windmills of ancient Persia, the use of natural forces, such as gravity or wind power, has helped the human race to survive.

Innovative engineering ideas have also emerged in more recent centuries, including the industrialisation of the 18th century, which produced steam power, and later, wind power. As a result of such developments, there are many wind turbines around the world which, e.g., deliver water to farms in Texas or mill grain in Europe.

This study deals with one such engineering structure that was successfully used to improve agricultural efficiency and raise the quality of life of the Polish family living in the Polish city of Poznan in the early 20th century (see Fig. 1). The history of this structure is as exciting as its engineering, which will be described in a later section. Poland was in a unique position at the 
end of the 18th century, wedged between three powerful empires that were supported by different local interest groups; ultimately, this resulted in the partitioning of the country. A hundred years later, Poland was still partitioned, and Poznan was under the control of the Kinngdom of Prussia. However, Poznan's residents were able to retain some parts of their original culture. In 1908, the first local industrial exhibition was approved [1].

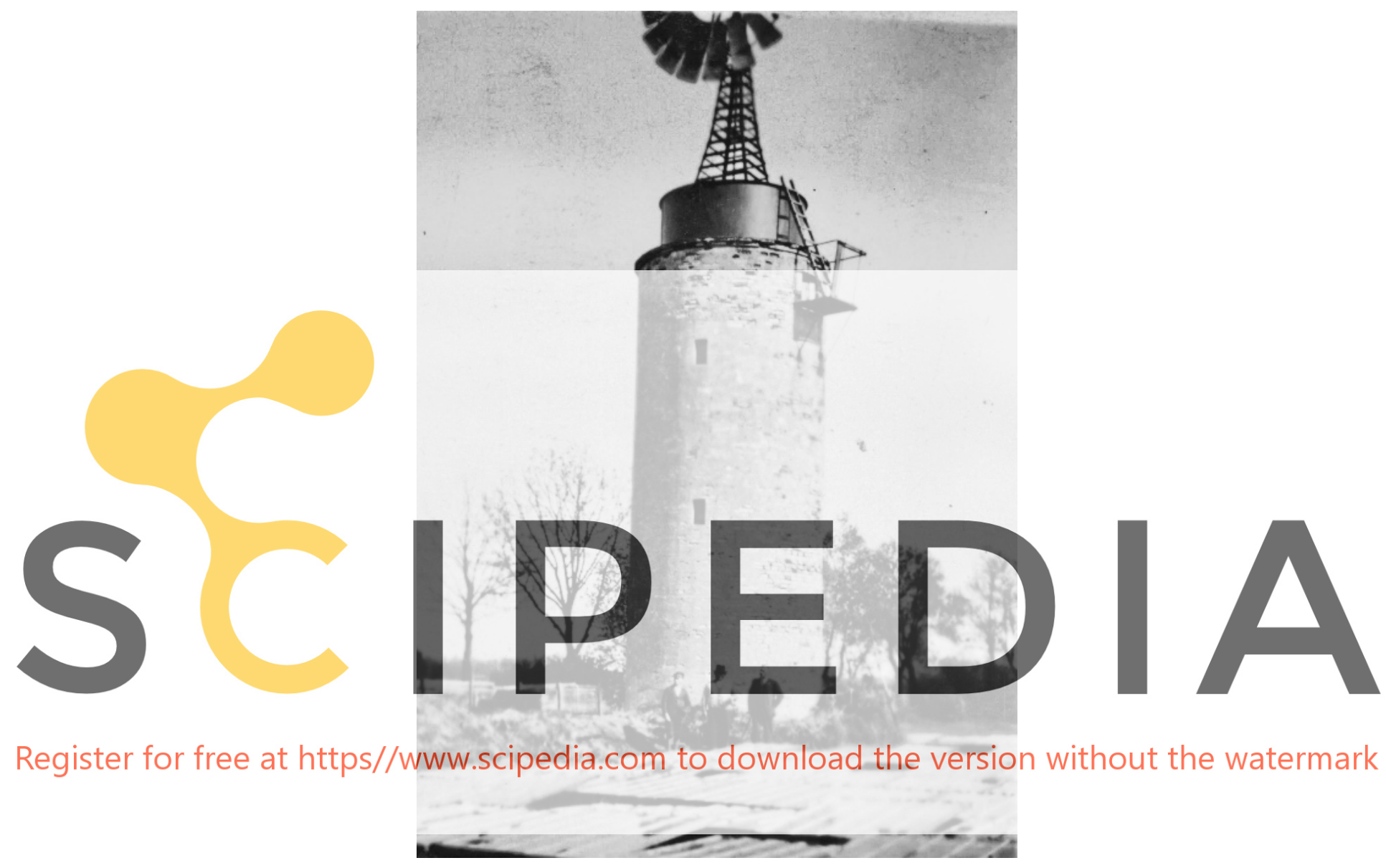

Figure 1: Wind turbine building: structure founder (middle) with family members [1920]

The exhibition included a presentation of Poznan's industrial achievements, including the engineering machines, tools and everyday items produced by Polish companies in the region and abroad, including Great Britain. Due to this exhibition, the local Polish community was optimistic and hopeful of becoming more competitive with other countries. Some important structures were built by locals immediately after this exhibition. One of them was the structure which is the focus of this paper. In 1910, in the area which is now the city centre, a Polish landlord built an advanced structure to automate his farming. Based on evidence from his family members and letters written at the time, he was inspired by the unique ideas on display at the Industrial Poznan Exhibition 1908 (original translation from Polish) and the concept of freely available power (i.e., wind energy).

At first glance, the structure was a classic windmill with a multi-blade wind turbine fixed to the top of a cylindrical masonry tower. Some additional elements illustrate the uniqueness of 
such a structure at the time. First, water was extracted from three independent inactive water points, located tens of meters away from the windmill. Second, the water was pumped to the steel reservoir located at the top of the structure, right beneath the wind turbine. Next, this efficient water source continuously supplied dozens of independent points located in the owner's fields and house, using only gravity. Finally, the most extraordinary use of this structure was the supply of electricity to the landlord's entire property.

One hundred years later, this heritage building is located in the centre of a rapidly growing area of Poznan. For this reason, restoration of the windmill is complex and requires the reconstruction of damaged or missing elements while observing new safety regulations. All these works must be performed without any of the original documentation and based only on photos from the beginning of the previous century.

In this work, the author present the basic assumptions which should underlie the future renovation process. Moreover, will propose a conceptual approach to designing elements which have disappeared due to age or damage, based on old photos and a 3D laser-scanning technique. One of the primary difficulties of the project is the existing masonry tower. The working wind turbine, together with a full water reservoir, may create a complex loading state for the mortar composite with which the original tower was constructed; therefore, author has designed a new support system for the turbine and the water tank. The design process was performed partially using numerical methods and employed the fluid-structure interaction methodology to predict displacement and stress outcomes. This methodology was applied to both the existing masonry

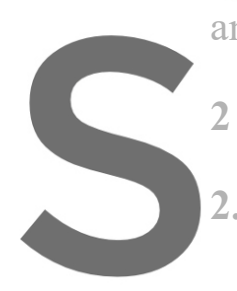
and the newly developed support system.

\section{WINI TURBINE BUILDING \\ 2.1 Description}

The paperwill now turn to the engineering
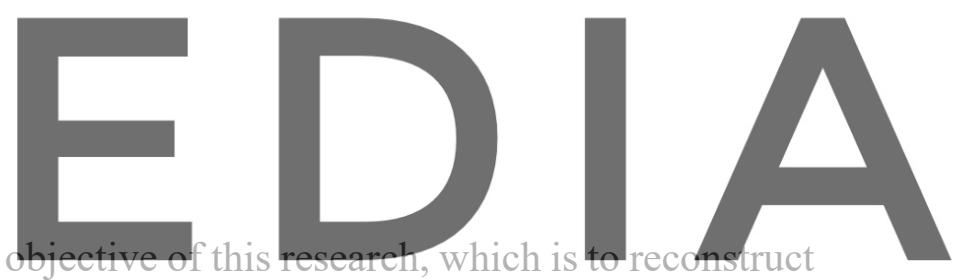

the wind turbine and modernise the supply system used to manage water in the structure. The

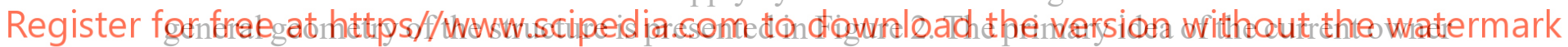
was to upgrade the existing water supply system by developing a new system in which the water source would not be dependent on actual ground water conditions. This means that the water would be stored in the previously constructed reservoir.

According to the original builder, there were ten crucial elements for the proper functioning of this device (see Figure 2): 1- the system that extracted water from the three independent water points located outside the structure, 2 - the water pumping system powered by the vertical movement of the steel rod, 3 - the masonry supporting the tower, which was responsible for absorbing the forces of 15 tons of water, the wind turbine and all other dynamic forces caused by the wind, 4 - the steel reservoir supported directly by the tower, 5 - the steel frame supporting the turbine, 6 - the steel turbine with eighteen blades, 7 - the direction and safety wings, 8 - the gearbox responsible for the safety system and for transferring the rotational movement of the turbine to the vertical movement of the steel bar, 9 - the water overload valve, 10 - the water distribution system, with more than $2,000 \mathrm{~m}$ of piping located up to $300 \mathrm{~m}$ from the structure, and 11 - the conservation entrance to control the structure. 


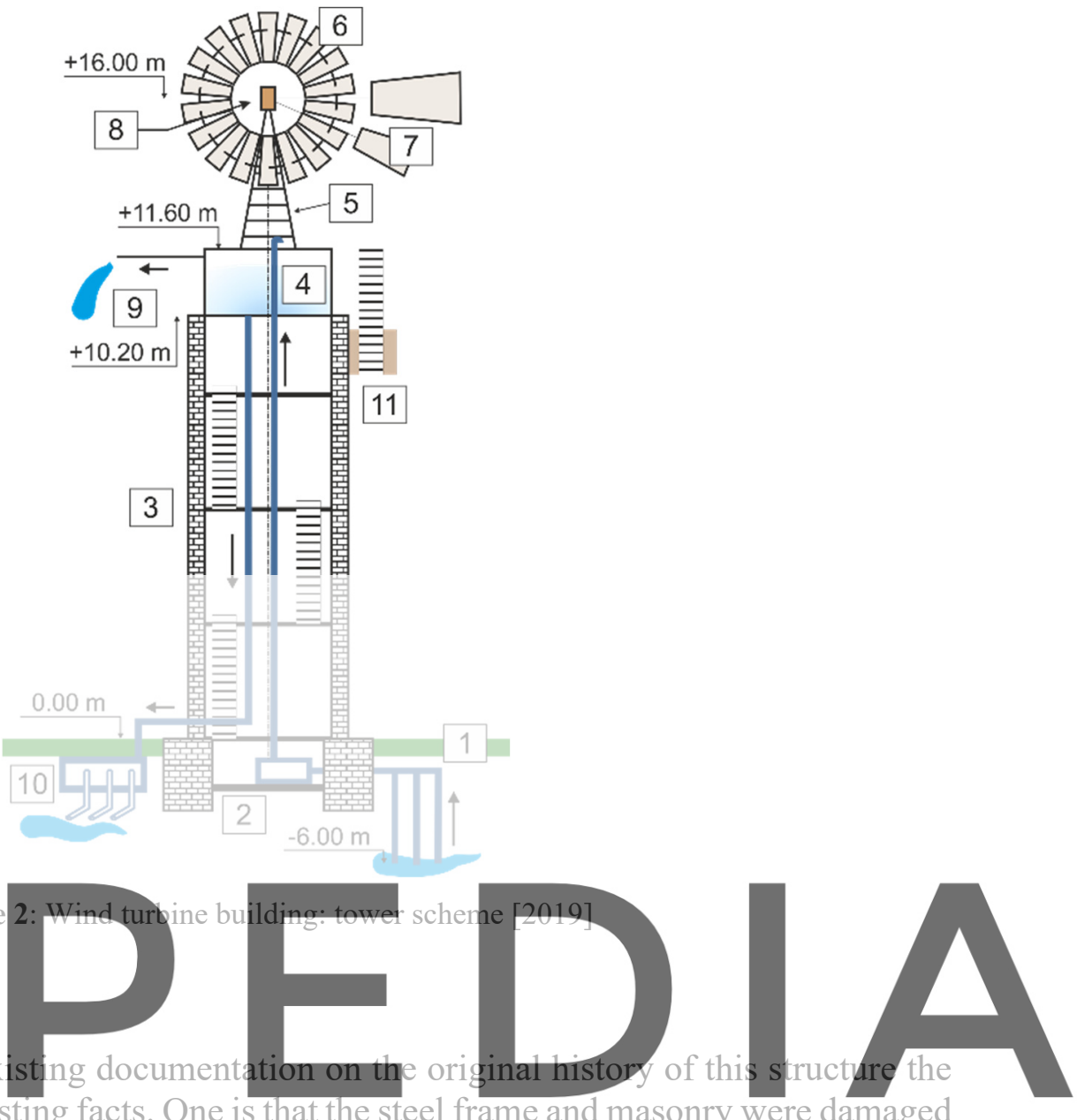

2.2 Measurements During the collection of existing documentation on the original history of this structure the
thor discovered some interesting facts. One is that the steel frame and masonry were damaged author discovered some interesting facts. One is that the steel frame and masonry were damaged

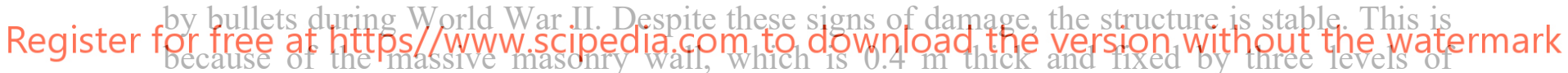
horizontal beams. This kind of irregularity in the structure's geometry shape was easily captured using 3D laser-scanning techniques. Surphaser HXS tool was used to capture millions of points from the structure. A partial view of the laser scan is presented in Figure 3.
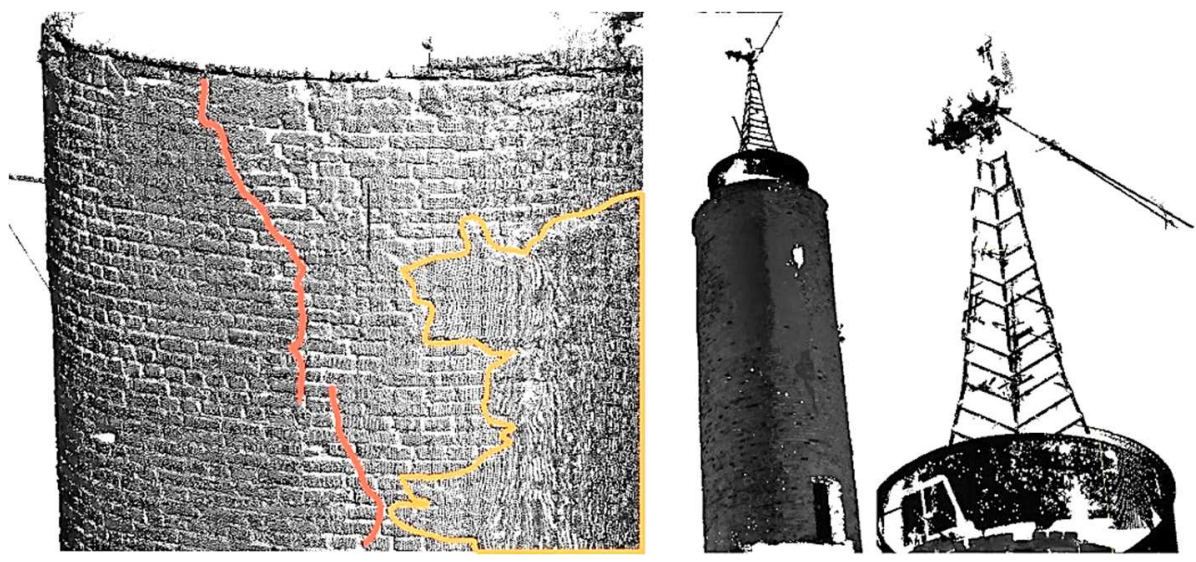

Figure 3: Wind turbine building: pre-processing 3D laser scan [2020] 
A detailed analysis of the thickness and regularity of the shape of the mortar joints allowed me to confirm all locations in which the masonry had been rebuilt. The red line in Figure 3 shows the edge on the external side, which was covered by the brick units after it was damaged during the war. An additional effect in Figure 3 illustrates the geometry of the steel elements, based only on $3 \mathrm{D}$ modelling. The orange line shows areas with the original plaster design, which is more than 100 years old.

The next step was the collection of data to identify the geometry of the wind turbine. The pictures provided by the family members of the original builder allowed me to confirm the geometric dimensions of the primary elements of the turbine, including the blades and gearbox. This data was transferred to the 3D model to assess the stress-displacement outcomes for different loading scenarios.

\section{RESTORATION PROPOSAL}

\subsection{Concept}

Due to the rapidly growing area around the wind turbine, the need for the reconstruction is accepted by the current owner and city administration. The primary goal for the renovation includes the reconstruction of all elements to enable them to be viewed by visitors interested in such an engineering structure. The most important parts of the structure which would be incorporated into the original wind turbine concept are:
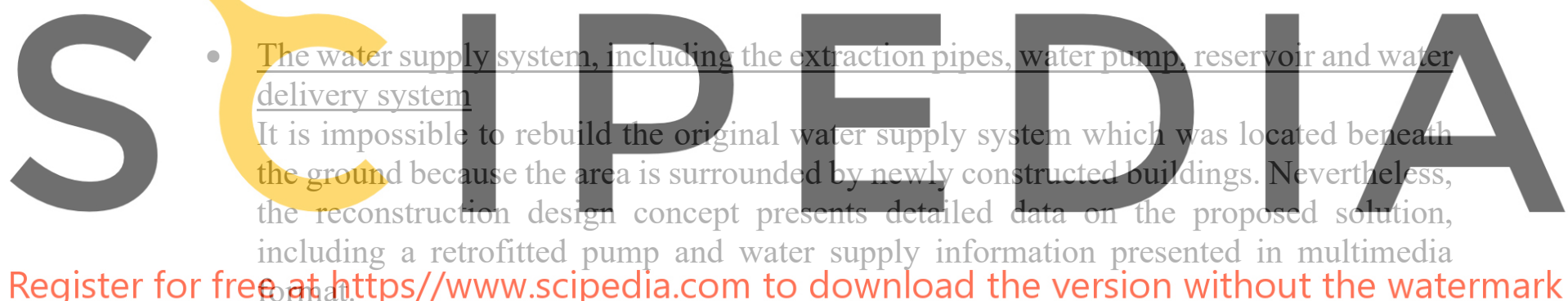

\section{Register for freematdattps//www.scipedia.com to download the version without the watermark}

- The masonry structures, including the foundation and cylindrical tower

This structural element is crucial because it is located in the centre of the proposed walking path. Thus, people will be able to walk very near the structure. The simple cylindrical form includes thick walls. However, the existing mortar is damaged by age, and the structure is unstable. For that reason, the author considers that the best solution is the construction of a new supporting structure inside the masonry tower. This precast steel spatial frame should be fixed to the new foundation. Moreover, the engineering design must include a dynamic-force loading scenario caused by the rotating wind turbine and a full water reservoir.

- The blade turbine, including the supporting bar frame, turbine wheel, gearbox and $\underline{\text { control and safety mechanisms }}$

Multi-blade turbines are commonly used around the world. However, the geometry of this windmill is different from that of other turbines identified in the literature $[2,3,4]$. Rebuilding the wings and other elements connected with the capture of wind power is 
relatively simple and is based on other wind turbines with similar dimensions. However, the gearbox system, including a safety mechanism for use in high wind conditions, must be designed from scratch.

\subsection{Numerical support}

Numerical techniques can credibly be used for structures for which default approaches and standardisation are impossible, such as heritage structures, which typically involve irregular geometry, ageing material and structural damage. Renovation processes have been supported using numerical knowledge since the first finite element codes. In this research, Abaqus code was used to assess the primary stress-displacement state under original and present-day loading scenarios. The numerical solution related to the renovation concept presented in the previous section can be separated into several independent problems. The first relates to the steel turbine and includes the dynamic response of the supporting frame structure and mechanisms inside the gearbox. The second relates to the performance of the masonry tower under static as well as dynamic loading caused by the rotating turbine wheel and wind fluctuations.

The stress-strain relation under consideration is based on the actual unit-mortar specimens. Moreover, concrete damage plasticity (CDP) behaviour has been applied numerically to estimate the potential for extraordinary cracking of the masonry under critical wind loading. The numerical design of the multi-blade wheel is another challenge. The static stressdisplacement currently observed is the result of more than $1000 \mathrm{~Pa}$ of static wind pressure and

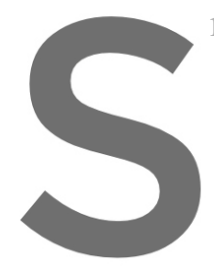
neglect for the rotation

\section{Register for free at https//www.scipedia.com tron}

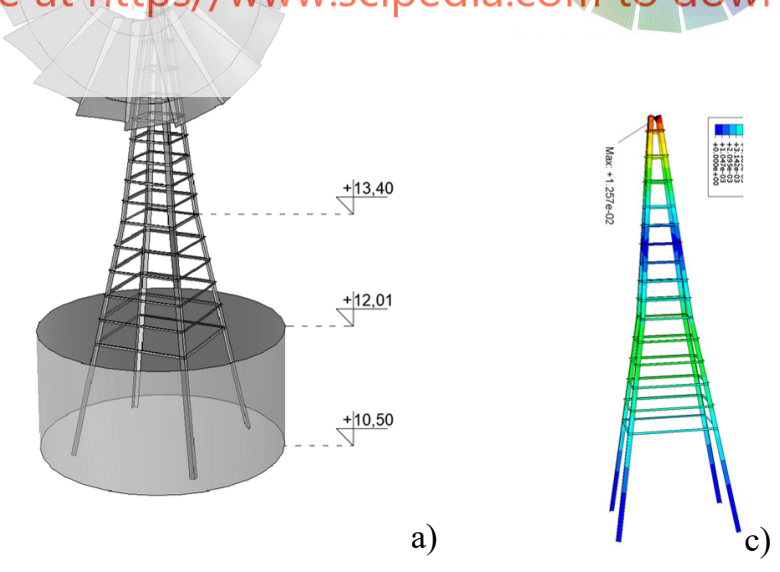

a)
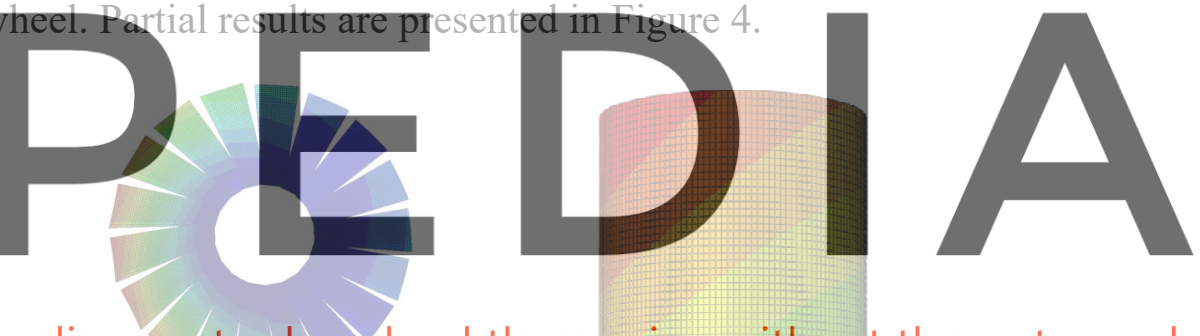
b)

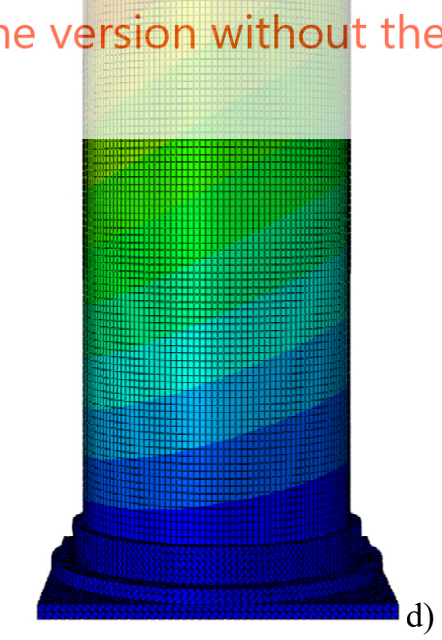

Figure 4: Numerical results of the static wind pressure modelling: a) CAD model of the wind turbine wheel, supporting bar frame and reservoir, b) displacement results for the static wind loading under a random angle of action, c) supporting frame displacement under maximum wind force transferred from the turbine wheel, and d) masonry tower displacement map during CDP material calibration process [5] 


\section{CONCLUSION}

This paper deals with a heritage engineering structure which is currently being restored. One of the crucial steps in the restoration process has been the collection and renewal of missing documentation. The design has been solely based on an examination of existing structural elements, many of which are missing due to the structure's more than 100-year history, and a careful review of photographs supplied by family members of the original builder.

In this study, the initial data were collected, and numerical results were obtained to support the future directions of the renovation and enable the restoration of the structure to its full functionality as it was at the beginning of the previous century. The preliminary numerical static solutions have allowed me to predict the structure's likely behaviour in various scenarios and confirm the utility of the proposed renovation solutions, including, for example, a prefabricated steel frame that will lessen the load on the existing masonry walls.

Acknowledgements. The author would like to thank all family members of the structure's original owner for supporting this research by providing authenticated pictures and original family documents. The author would also like to thank the Poznan Historical Preservation Office for providing access to official heritage resources.

Furthermore, the author would like to ask anyone with data supporting the viability of the similar wind turbine building restoration (e.g., pictures or designs of similar structures around

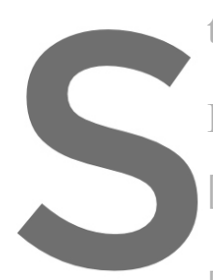
the world) to contact.

REFERENCES

[1] Gustowski A., Pamiętnik Biblioteka Cyfrowa 2018
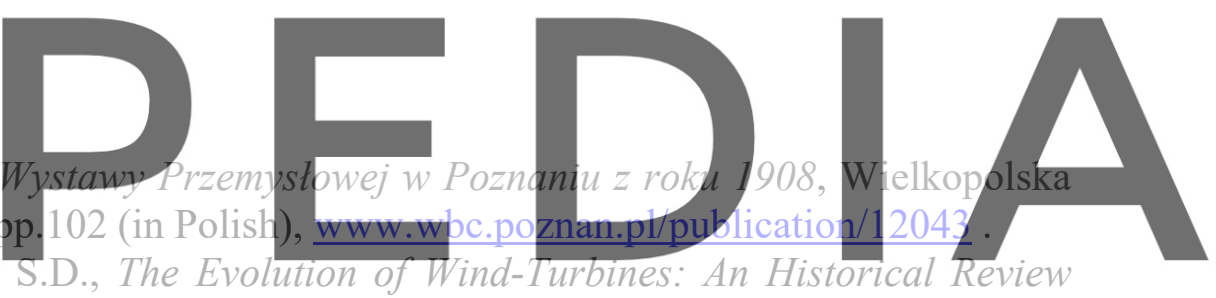

[2] Fleming P.D. and Proben S.D., The Evo

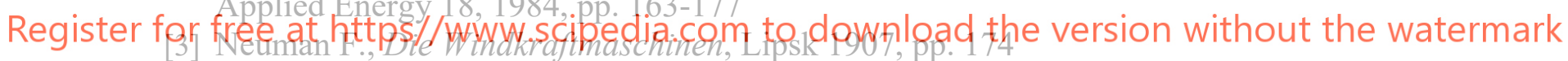

[4] Szowheniw J., Silniki Wietrzne [elektrownie wiatrowe], Polski Komitet Energetyczny, Warszawa 1932, pp. 182 (in Polish).

[5] Dybizbanski J., Leszkiewicz J., Projekt rekonstrukcji zabytkowej turbiny wietrznej, Poznan University of Technology 2020, BSc thesis, pp.50 (in Polish). 